\title{
Temperature and host effects on key morphological characters of Hemisarcoptes cooremani and Hemisarcoptes malus (Acari: Hemisarcoptidae)
}

\author{
Marilyn A. Houck ${ }^{\mathrm{a} *}$ and Barry M. OConnor ${ }^{\mathrm{b}}$ \\ ${ }^{a}$ Department of Biological Sciences, Texas Tech University, Lubbock, TX 79409, USA \\ ${ }^{\mathrm{b}}$ Museum of Zoology and Department of Biology, University of Michigan, \\ Ann Arbor, MI 48109,USA
}

(Received 12 June 1996; accepted 1 October 1996)

\begin{abstract}
We investigated the influence of temperature and resources on six morphological characters thought to distinguish two North American species of Hemisarcoptes ( $H$. malus and $H$. cooremani). We raised mites at three temperatures $\left(15,24\right.$ or $\left.30^{\circ} \mathrm{C}\right)$ and on two different scale insect prey (Aspidiotus nerii or Aonidiella aurantii) which were cultured on two different substrates (potato tubers and lemon fruit). In general, the temperature had more of an influence on the character variation than did the host and the highest temperature resulted in the smallest mean body size. The two species did not respond to changes in the temperature or host in a symmetrical fashion. The temperature significantly influenced the lengths of the external scapular setae (sce) of $H$. malus and the sce and first coxal setae (la) of $H$. cooremani. The relative lengths of the setae $s c e$ and $I a$ of $H$. cooremani were significantly influenced by the temperature, while the host type significantly influenced the paraproctal setae $\left(p s_{2}\right)$. Major-axis regressions indicated that $H$. cooremani had an absolutely longer mean setal length for $l a$ and for $p s_{2}$, than $H$. malus, but a relatively shorter sce. An ANOVA of the size-adjusted shield characters of $H$. malus resulted in non-significant effects of the temperature or host on either the prodorsal shield area or circumference. The temperature, but not the host, statistically influenced the shield circumference and area in H. cooremani. Regressions of the shield area (size) on body length, resulted in two clear groupings by species. Hemisarcoptes cooremani had an absolutely larger shield area and increased circumference (complexity), as compared to $H$. malus. A plot of the shield circumference in relation to the shield area, however, resulted in a single trajectory, indicating that shield complexity is an allometric consequence of an increase in body size in both species. Though characters can be influenced significantly by environmental parameters, the speciesspecific patterns of some characters of North American Hemisarcoptes are distinctive enough to allow diagnosis and identification.
\end{abstract}

Key words: Acari, character variance, ecophenotypic plasticity, mites.

* To whom correspondence should be addressed at: Tel: 806-742-2459; Fax: 806-742-2963;

e-mail: YIMAH@TTACS.ttu.edu

0168-8162 C 1996 Chapman \& Hall 


\section{INTRODUCTION}

Mites of the genus Hemisarcoptes (Acari: Acariformes) are obligate parasites of armoured scale insects (Coccoidea: Diaspididae) (Houck and OConnor, 1990). The genus is widely distributed throughout the northern hemisphere, Africa, the Oriental region and Australia. Across its geographic range, the genus is morphologically conservative with few distinguishing characters expressed between species. As part of a systematic revision of the genus, we have looked for key morphological characters in the five nominal species and a number of undescribed species.

Two nominal species of Hemisarcoptes occur in North America: Hemisarcoptes malus (Shimer, 1868) and Hemisarcoptes cooremani (Thomas, 1961). Hemisarcoptes malus is distributed throughout most of the northern and central United States and southern Canada. Hemisarcoptes cooremani occurs from the southern United States to northern South America and the Caribbean region. Hemisarcoptes malus and H. cooremani are central to the work reported here because they are currently being used by American and Israeli workers in a biocontrol programme and an accurate discrimination of species is required for this purpose.

This paper investigates the morphological stability of six characters, previously determined to potentially have diagnostic qualities in distinguishing the two North American species. The characters examined in this study include the total body length, the area and circumference of the prodorsal shield and the mean lengths of the external scapular setae (sce), the first coxal setae (1a) and the paraproctal setae $\left(p s_{2}\right)$. The nomenclature for the idiosomal setae follows Griffiths et al. (1990). The prodorsal shield represents the only rigid sclerotized structure present on the dorsum of these mites (Fig. 1A). The shield area is used here as an estimator of the overall shield size and the circumference (standardized with respect to area) is a proxy for the shield complexity. The shield of $H$. malus is qualitatively different from that of $H$. cooremani (Fig. 2). In $H$. malus, the anterior portion of the shield is somewhat triangular, the subocular area somewhat heart shaped and the shield does not abut the ocelli. The anterior portion of the shield of $H$. cooremani is square-shaped, the subocular area is expanded posteriorly and the shield is inclined to adjoin the ocelli. Clearly there appear to be qualitative differences in the shields of the two species and we wanted to test whether the shield would be consistently diagnostic across the range of environmental parameters.

The three other characters which distinguished the two species in a previous study were the lengths of three setae: the external scapular setae (sce) of the prodorsal region, the first pair of coxal setae $(l a)$, and the paraproctal setae $\left(p s_{2}\right)$ (Fig. 1A and B).

In a parallel multivariate study of the nominal species of Hemisarcoptes (Houck and OConnor, ms.), we examined the morphological variation and static 

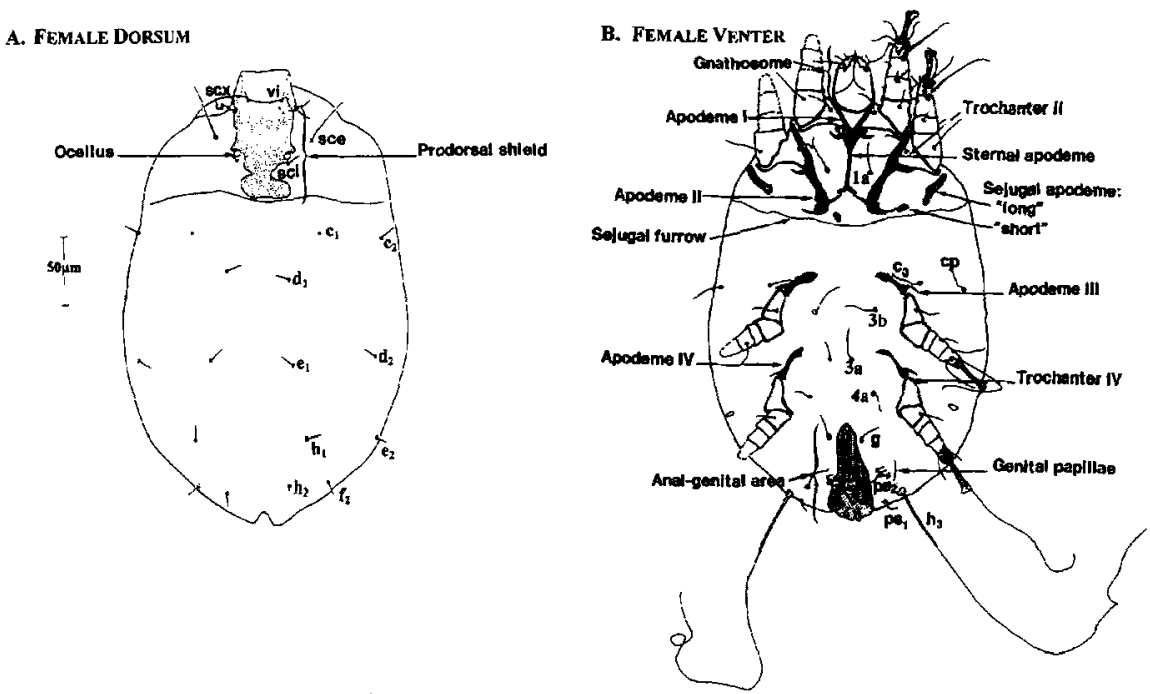

Fig. 1. Anatomical morphology of Hemisarcoptes. (A) Dorsum of $H$. cooremani. (B) Venter of $H$. malus.

Hemisarcoptes malus

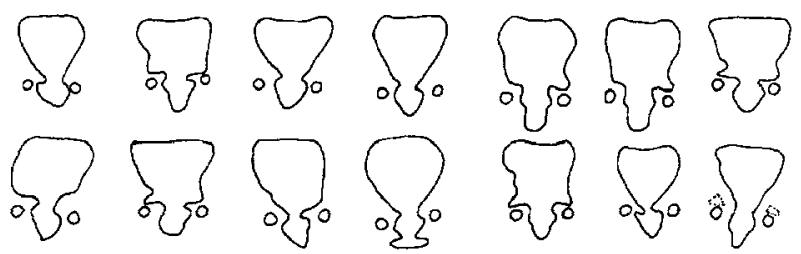

Hemisarcoptes cooremani

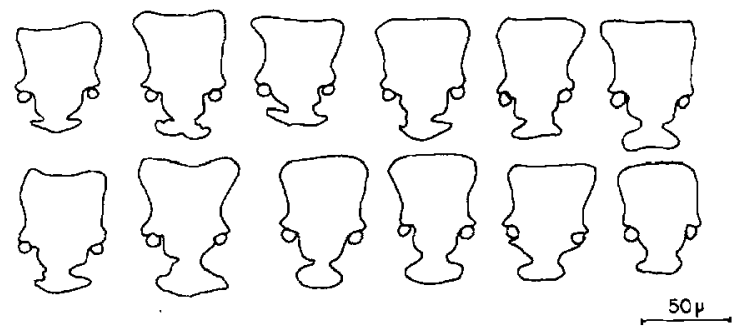

Fig. 2. Camera-lucida tracings of the prodorsal shield of randomly selected representatives of $H$. malus and $H$. cooremani. 
allometric aspects of the adult morphology. In relation to the present work, four findings were derived from that study: (1) the males and females were completely dimorphic in body size, (2) although all four taxa examined were discriminated via a size-independent discriminant function analysis, the character variation expressed among males was much less than that for females, (3) males lacked interspecific diagnostic characters and (4) there were significant static allometric differences in females, which were also correlated with the differences in the total body size. Because the male morphology was relatively uninformative, the present work concentrates on the character variation among females, using the previously determined diagnostic characters as a focus. In particular, we address the following questions.

(1) How are the female body length, prodorsal shield circumference and area and the lengths of three potentially diagnostic setae influenced by temperature and resources within an ontogeny?

(2) Are the setal lengths of females sufficiently stable across temperature and resources to be reliable discriminatory characters under a range of experimental conditions?

(3) What general statements of character variance and habitat variability may extend from this study?

\section{MATERIALS AND METHODS}

\section{Stock cultures}

Stocks of Hemisarcoptes were field collected from diaspidid hosts as follows: $H$. malus from Lepidosaphes ulmi on apple bark in the vicinity of Ithaca, New York and $H$. cooremani from Lepidosaphes beckii on citrus near Donna, Texas. The mites were transported to the laboratory where axenic cultures were expanded on the diaspidid Aspidiotus nerii (oleander scale) grown on potatoes. The stock cultures were maintained in $16 \mathrm{ft}^{3}$ incubators at $24^{\circ} \mathrm{C}$. Open trays of water were placed beneath the cultures and fans within the units provided air circulation. The humidity was not controlled, but remained relatively consistent at $100 \%$ saturation.

Monoculture stocks of adult mites were incubated under these conditions until they produced first-generation eggs. This protocol provided both species of mites with a common conditioning experience, but did not allow sufficient time for significant genetic selection effects to have occurred in the culture prior to treatment.

\section{Experimental treatment}

Laboratory studies were designed to simulate the potential range of environmental factors encountered by the mites and test the degree of character variation correlated with environmentally realistic regimes. We tested the 
temperature at three experimental levels $\left(15,24\right.$ and $\left.30^{\circ} \mathrm{C}\right)$ and the resource base at two levels (A. nerii grown on potatoes and Aonidiella aurantii cultured on lemons). The 15 and $30^{\circ} \mathrm{C}$ temperatures represent the lower and upper limits of tolerance for scale insect survival. The two diaspidids represent important contrasts in both morphology and plant-host type. Aspidiotus nerii has a convex cap and no velum. Aonidiella aurantii is flat in profile and has a ventral velum. Another obvious difference was that the plant substrate upon which the scales were grown offers contrasts. Aspidiotus nerii was presented to the mites on starch-laden plant tubers, while $A$. aurantii was incubated on acidic citrus fruits (lemons). No distinction was made in this study between the influence of scale host species and scale host resource (potato or lemon) in defining the resource base for the mite.

Using a dissecting microscope, first-generation eggs of mites were collected from the host ( $A$. nerii) by lifting the scale cap and locating the eggs. Eggs were collected from monocultures of $\mathrm{H}$. malus and $\mathrm{H}$. cooremani and placed under the scale cap of one of the two treatment scale species. Ten replicates from each resource treatment group were maintained at each of the three experimental temperatures. The combinations of species: temperature : resource represent a $2 \times 3 \times 2$ statistical block design. The first-generation eggs of Hemisarcoptes were cultured at the chosen temperature-resource combination until reaching adulthood.

\section{Data collection}

The first-generation adult female mites were collected, cleared in lactophenol and mounted on microscope slides using Hoyer's medium. Camera-lucida drawings were produced using a Wild M-20 phase-contrast microscope. From these drawings a series of points along the length of each seta and along the perimeter of the prodorsal shield was electronically converted to Cartesian coordinates using a digitizing pad (Houston Instrument Hipad DT-114) and an IBM PC microcomputer. The setal lengths and shield circumference were determined by summing the Euclidean distances between consecutive points. The shield area was computed using the method of Harvey (1981). All the measurements were scaled in micrometres.

The total body length was measured within and between treatments. Because the body size may be responsible for (or contribute to) character differences between the experimental groups, the size effects were partitioned from the data by regressing the logarithm of each character on the logarithm of the body length and using the residuals in subsequent statistical comparisons. This allowed biological patterns to be interpreted as size-free contrasts, independent of the allometric consequences of the mean size differences between the groups. Analyses of variance were carried out on pooled regression residuals using the general linear model. Statistical differences $(p=0.05)$ were determined using Tukey's studentized range test (SAS Institute, 1982). 


\section{RESULTS}

Effect of temperature on body length

The mean body length data for $H$. malus and $H$. cooremani are given in Table 1 . In general, the highest culture temperature $\left(30^{\circ} \mathrm{C}\right)$ resulted in the smallest mean body size for females of both species. However, in only one case (i.e. $30^{\circ} \mathrm{C}$ for $H$. malus) was the difference statistically significant $(p=0.008)$, as determined by MANOVA.

When the body lengths for $H$. malus and $H$. cooremani were pooled across the temperature and resources, they were significantly different from one another ( $p=0.004$, two-tailed test) with $H$. cooremani (mean $=329 \mu \mathrm{m}$ ) being larger than $H$. malus (mean $=300 \mu \mathrm{m}$ ). The analysis of variance procedure indicated that the species and temperature significantly influenced the body length ( $p<0.0001$ in both instances), but resources did not $(p=0.831)$. The interaction terms indicated that there was not a significant temperature-resource interaction $\left(F_{2,190}=0.24, p=0.785\right)$, a significant interaction between the species and resources $\left(F_{1,190}=2.72, p=0.100\right)$ or an interaction between the species, temperature and resources $\left(F_{2,190}=1.81, p=0.166\right)$.

Occasionally, extreme teratogenic effects were observed in the mites cultured at $30^{\circ} \mathrm{C}$, primarily the degeneration of legs IV. It is not clear whether this reflects a sudden shift in the developmental temperature of as little as $6^{\circ} \mathrm{C}$ (from 24 to $30^{\circ} \mathrm{C}$ ) which can provoke serious morphological consequences or whether higher temperatures themselves represent a significant ontogenetic stress.

Temperature and resource effect on setal lengths

The temperature significantly influenced the length of seta sce for $H$. malus (Fig. 3; analysis of variance given in Table 2) with the sce being shortest at $30^{\circ} \mathrm{C}$. The

TABLE 1

Summary of mean total body length measurements for $H$. malus and $H$. cooremani at the three treatment temperatures and on alternate hosts

\begin{tabular}{llll}
\hline Host & $15^{\circ} \mathrm{C}$ & $24^{\circ} \mathrm{C}$ & $30^{\circ} \mathrm{C}$ \\
\hline H. malus & & & \\
A. aurantii (lemon) & $299 \pm 29$ & $302 \pm 19$ & $281 \pm 24^{\mathrm{a}}$ \\
$\begin{array}{l}\text { A. nerii (potato) } \\
\text { H. cooremani }\end{array}$ & $300 \pm 18$ & $295 \pm 23$ & $278 \pm 23^{\mathrm{a}}$ \\
A. aurantii (lemon) & $325 \pm 22$ & $326 \pm 11$ & $322 \pm 23$ \\
A. nerii (potato) & $344 \pm 34$ & $334 \pm 32$ & $330 \pm 22$ \\
\hline
\end{tabular}

a Statistically significant difference ( $p=0.05$ ), Tukey's studentized range test. 


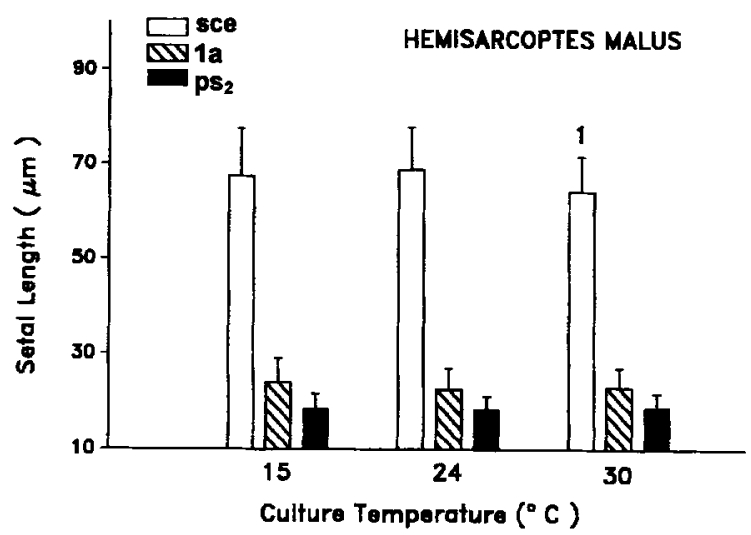

Fig. 3. Relationship between the setal length and temperature for $H$. malus. The bars represent mean values $\left( \pm S D\right.$ ). The number 1 above the bar at $30^{\circ} \mathrm{C}$ represents the only pairwise contrast which is significantly different. sce, external scapular setae of the prodorsal region; $1 a$, the first pair of coxal setae; $p s_{2}$, paraproctal setae.

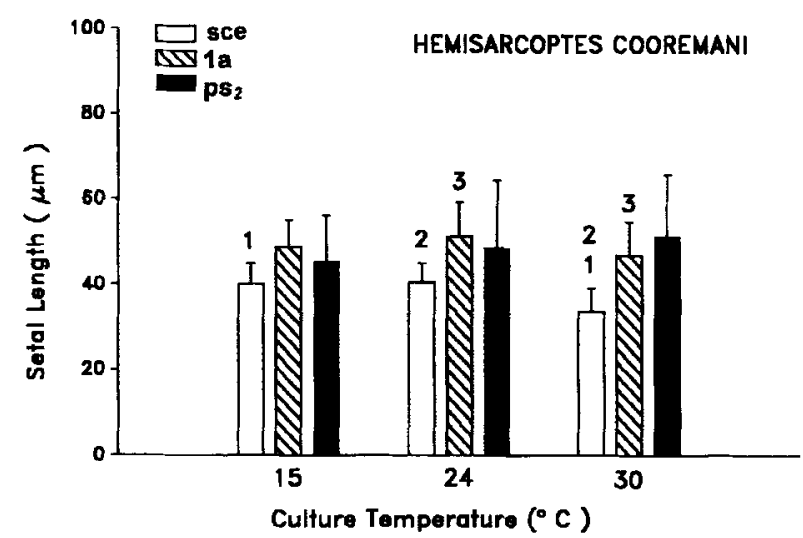

Fig. 4. Relationship between the setal length and temperature for $H$. cooremani. The bars represent mean values $( \pm S D)$. The numbers above the bars represent those pairwise contrasts which are significantly different from one another. sce, external scapular setae of the prodorsal region; $l a$, the first pair of coxal setae; $p s_{2}$, paraproctal setae.

temperature significantly influenced the length of setae sce and $1 a$ for $H$. cooremani (Fig. 4; analysis of variance given in Table 2). The sce was significantly longer at culture temperatures of 15 and $24^{\circ} \mathrm{C}$ as compared to $30^{\circ} \mathrm{C}$ and $l a$ was significantly longer at $24^{\circ} \mathrm{C}$ as compared to mites cultured at $30^{\circ} \mathrm{C}$. The lengths of the paraproctal setae $\left(p s_{2}\right)$ of $H$. malus and $H$. cooremani were not significantly influenced by the temperature. 
TABLE 2

Summary of the analysis of variance of setal lengths (unadjusted for size) for $H$. malus and $H$. cooremani

\begin{tabular}{|c|c|c|c|c|c|c|}
\hline & \multicolumn{3}{|c|}{ H. malus $(n=120)$} & \multicolumn{3}{|c|}{ H. cooremani $(n=96)$} \\
\hline & sce & $1 a$ & $p s_{2}$ & sce & $1 a$ & $p s_{2}$ \\
\hline Temperature & $\begin{array}{l}F=3.88 \\
p=0.02^{\mathrm{a}}\end{array}$ & $\begin{array}{l}F=0.98 \\
p=0.38\end{array}$ & $\begin{array}{l}F=0.17 \\
p=0.84\end{array}$ & $\begin{array}{l}F=21.25 \\
p=0.0001^{\mathrm{a}}\end{array}$ & $\begin{array}{l}F=3.24 \\
p=0.04^{\mathrm{a}}\end{array}$ & $\begin{array}{l}F=1.17 \\
p=0.31\end{array}$ \\
\hline Host & $\begin{array}{l}F=0.80 \\
p=0.37\end{array}$ & $\begin{array}{l}F=0.02 \\
p=0.89\end{array}$ & $\begin{array}{l}F=2.54 \\
p=0.11\end{array}$ & $\begin{array}{l}F=1.31 \\
p=0.26\end{array}$ & $\begin{array}{l}F=3.36 \\
p=0.07\end{array}$ & $\begin{array}{l}F=18.59 \\
p=0.0001^{\mathrm{a}}\end{array}$ \\
\hline
\end{tabular}

a Statistically significant difference $(p=0.05$ ), Tukey's studentized range test.

sce, external scapular setae of the prodorsal region; $l a$, the first pair of coxal setae; $p s_{2}$, paraproctal setae.

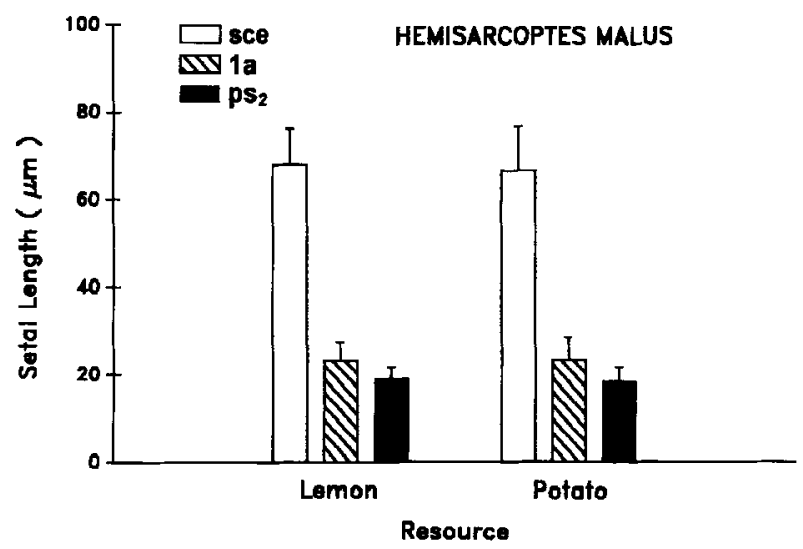

Fig. 5. Relationship between the setal length and host for $H$. malus. The bars represent mean values ( $\pm \mathrm{SD}$ ). sce, external scapular setae of the prodorsal region; la, the first pair of coxal setae; $p s_{2}$, paraproctal setae.

The temperature and resources had no effect on the setal lengths of $H$. malus (Fig. 5 and Table 2) and only a limited influence on $H$. cooremani (i.e. $p s_{2}$; Fig. 6 and Table 2). The lengths of the paraproctal setae of $H$. cooremani grown on A. aurantii (on lemons) were shorter than those grown on $A$. nerii (on potatoes).

A MANOVA analysis of the significant interaction terms for the treatment variables indicated that the species per se had an effect on the setal lengths $(p \geqslant 0.001)$ and that the temperature had a significant effect $(p \geqslant 0.0001)$, but resources did not $(p=0.831)$. The interaction of species and resources was not significant $(p=0.101)$ nor was the interaction term for the temperature and resources $(p=0.785)$. Because the resources and temperature were not confounded it is justifiable to discuss the data by resources and temperature separately. 


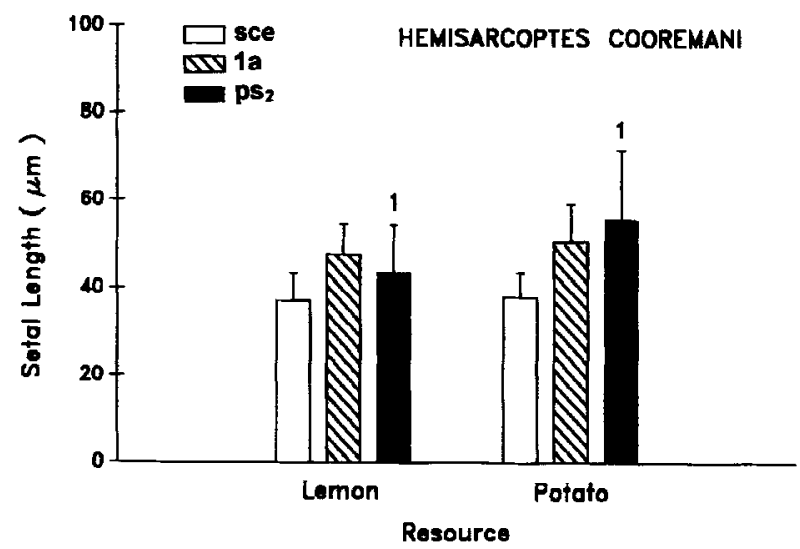

Fig. 6. Relationship between the setal length and host for $H$. cooremani. The bars represent mean values $( \pm S D)$. The numbers above the bars represent those pairwise contrasts which are significantly different from one another. sce, external scapular setae of the prodorsal region; $I a$, the first pair of coxal setae; $p s_{2}$, paraproctal setae.

TABLE 3

Summary of the analysis of variance of size-adjusted setal lengths for $H$. malus and $H$. cooremani

\begin{tabular}{|c|c|c|c|c|c|c|}
\hline & \multicolumn{3}{|l|}{$H$. malus } & \multicolumn{3}{|l|}{ H. cooremani } \\
\hline & sce & $1 a$ & $p s_{2}$ & sce & $I a$ & $p s_{2}$ \\
\hline Temperature & $\begin{array}{l}F=2.25 \\
p=0.11\end{array}$ & $\begin{array}{l}F=0.67 \\
p=0.52\end{array}$ & $\begin{array}{l}F=1.86 \\
p=0.16\end{array}$ & $\begin{array}{l}F=26.53 \\
p=0.0001^{\mathrm{a}}\end{array}$ & $\begin{array}{l}F=4.82 \\
p=0.01^{\mathrm{a}}\end{array}$ & $\begin{array}{l}F=0.66 \\
p=0.52\end{array}$ \\
\hline Host & $\begin{array}{l}F=0.63 \\
p=0.63\end{array}$ & $\begin{array}{l}F=0.04 \\
p=0.84\end{array}$ & $\begin{array}{l}F=2.48 \\
p=0.12\end{array}$ & $\begin{array}{l}F=1.47 \\
p=0.23\end{array}$ & $\begin{array}{l}F=3.02 \\
p=0.08\end{array}$ & $\begin{array}{l}F=18.66 \\
p=0.0001^{\mathrm{a}}\end{array}$ \\
\hline
\end{tabular}

${ }^{a}$ Statistically significant difference $(p=0.05)$, Tukey's studentized range test.

$s c e$, external scapular setae of the prodorsal region; $l a$, the first pair of coxal setae; $p s_{2}$, paraproctal setae.

\section{Allometric comparisons of setal lengths}

For $H$. malus, the size-adjusted setal lengths were not statistically different at any of the experimental temperatures or resources (Table 3). The relative lengths of two setae of $H$. cooremani (sce and $l a$ ) were significantly influenced by the temperature, while the resource type significantly influenced only the paraproctal setal length. These results are in line with those for the setal lengths when not corrected for body size, but indicate that the setal lengths measured on $H$. malus tend to be isometric while the patterns for $H$. cooremani deviate from those predicted on body size alone (allometric).

Major axis regressions of setal lengths, pooled across the resources and temperature, indicated an increase in the setal length relative to an increase in 

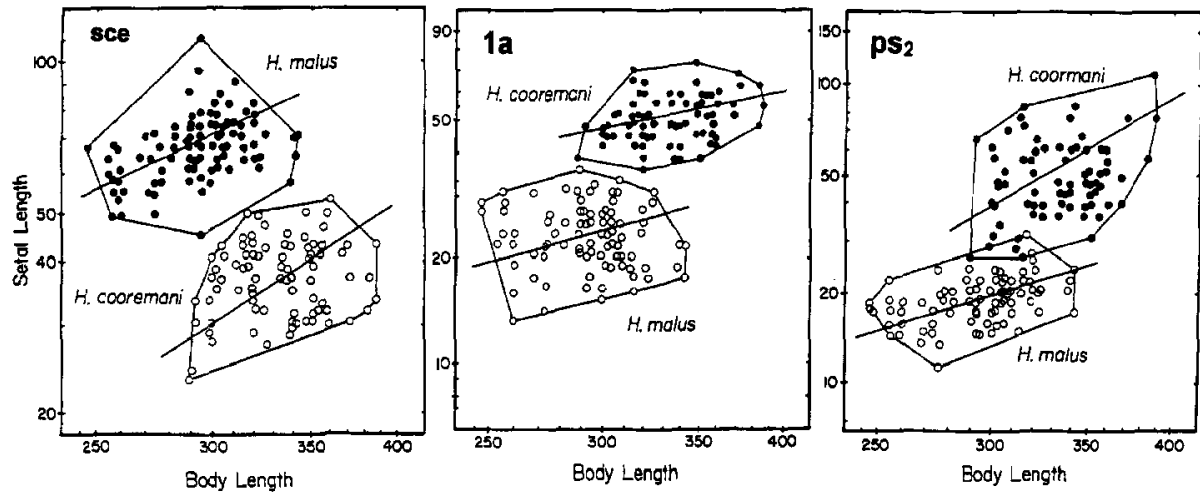

Fig. 7. The regression of the setal length against the body length for $H$. malus and $H$. cooremani. The lines of best fit were calculated using major-axis regression.

the body size for $H$. malus and $H$. cooremani for all three setae measured (Fig. 7). Hemisarcoptes cooremani had an absolutely longer mean setal length for $1 a$ and $p s_{2}$, but a relatively shorter mean setal length for sce as compared to $H$. malus. These differences were statistically significant. In addition, there was a greater increase in the relative paraproctal setal lengths with increasing body size (i.e. a greater allometric coefficient) in $H$. cooremani than in $H$. malus.

\section{Allometric comparisons of prodorsal shields}

Camera-lucida tracings of the prodorsal shield of $H$. malus and $H$. cooremani demonstrated apparent qualitative interspecific differences and an intraspecific variation in size and complexity (Fig. 2). Regressions of the shield area ('size') in relation to the body length, pooled across the temperature and resources, resulted in two clear groupings by species (Fig. 8). Hemisarcoptes cooremani had an absolutely larger shield size (mean $=2394 \mu \mathrm{m}^{2}, \mathrm{~N}=48$ ) and little overlap with that of $\mathrm{H}$. malus (mean $=1343 \mu \mathrm{m}^{2}, \mathrm{~N}=60$ ) even where the absolute body lengths were within equivalent ranges (e.g. at 290-340 $\mu \mathrm{m}$ ).

A comparison of the prodorsal shield circumference ('complexity') with the body length (Fig. 9) indicated that the shield of $H$. cooremani was more complex (mean $=232 \mu \mathrm{m}, \mathrm{N}=48$ ) than that of $H$. malus (mean $=173 \mu \mathrm{m}$, $\mathrm{N}=60$ ), with a minimal overlap in the ranges even where the body lengths were similar (e.g. at $310 \mu \mathrm{m})$. Both the shield area and circumference were weakly correlated with the total body length.

Though $H$. malus and $H$. cooremani clearly differed in the shield area and circumference, a plot of the shield circumference in relation to the shield area (Fig. 10) indicated a single size-complexity trajectory for the two species. No ad hoc explanation need be invoked concerning the evolution or function of the 


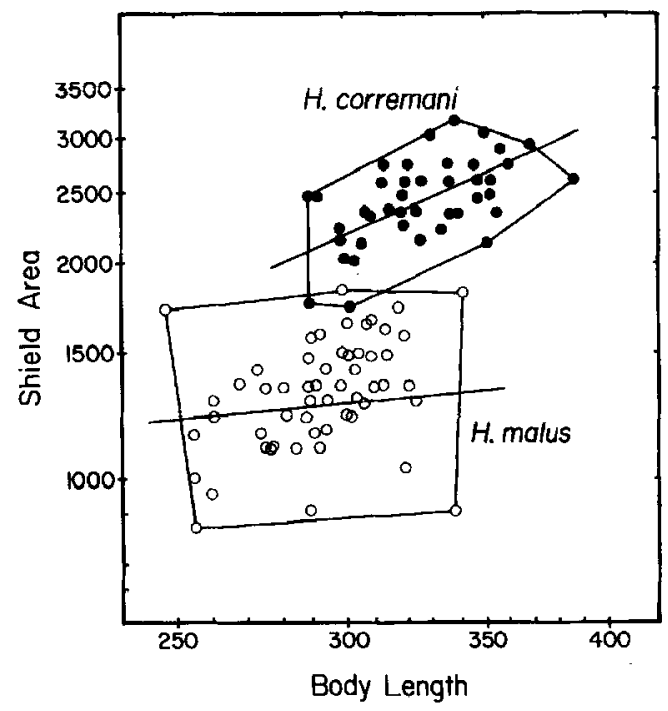

Fig. 8. The regression of the prodorsal shield area against the body length of $H$. malus and $H$. cooremani. The lines of best fit were calculated using major-axis regression.

increased prodorsal shield complexity in $H$. cooremani, as it represents an allometric extrapolation due to an increase in the shield area (positive allometry). An increase in the body length contributes naturally to the increased complexity of the shield, resulting in a continuous allometric transformation series by size.

An ANOVA of the size-adjusted shield characters resulted in non-significant effects of the temperature and resources on the prodorsal shield circumference $\left(R^{2}=0.07\right)$ and area $\left(R^{2}=0.03\right)$ for $H$. malus (Table 4). The temperature but not the resource type statistically influenced the shield circumference and area in $H$. cooremani. This effect is correlated with the weak influence of temperature on size, but indicates that the temperature has a relatively greater influence on the prodorsal shield than it does on the body length.

The temperature had an influence on the prodorsal shield of $H$. malus (Table 5). Pair-wise comparisons of the temperature effects indicated that the shield circumference in $H$. cooremani is significantly less for mites grown at $15^{\circ} \mathrm{C}$ as compared with those at $24^{\circ} \mathrm{C}$ and $30^{\circ} \mathrm{C}$ (Table 5). No statistically significant differences were found for mites cultured at $24^{\circ} \mathrm{C}$ as compared with those at $30^{\circ} \mathrm{C}$. This pattern is consistent with that for the shield area. Lower temperatures, which result in a larger body size, produce relatively smaller prodorsal shields with a relatively reduced area. The resources had no influence on the prodorsal shield characters for either species of mite. 


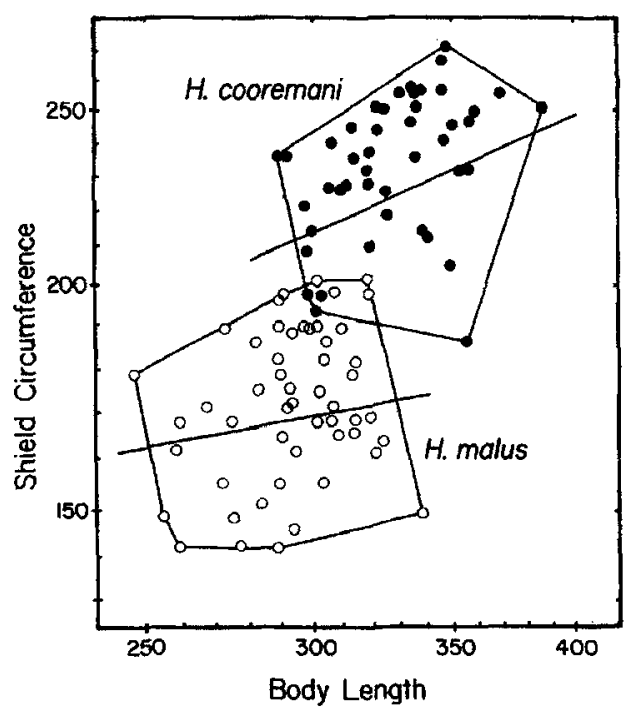

Fig. 9. The regression of the prodorsal shield circumference against the body length for $H$. malus and $H$. cooremani. The line of best fit was calculated using major-axis regression.

TABLE 4

Summary of the anaiysis of variance of size-adjusted shield characters for $H$. malus and $H$. cooremani

\begin{tabular}{|c|c|c|c|c|}
\hline & \multicolumn{2}{|l|}{ H. malus } & \multicolumn{2}{|l|}{ H. cooremani } \\
\hline & Circumference & $\operatorname{Area}^{\frac{1}{2}}$ & Circumference & $\operatorname{Area}^{\frac{1}{2}}$ \\
\hline Temperature & $\begin{array}{l}F=1.72 \\
p=0.19\end{array}$ & $\begin{array}{l}F=0.79 \\
p=0.46\end{array}$ & $\begin{array}{l}F=11.76 \\
p=0.0001^{\mathrm{a}}\end{array}$ & $\begin{array}{l}F=3.29 \\
p=0.05^{\mathrm{a}}\end{array}$ \\
\hline Host & $\begin{array}{l}F=0.58 \\
p=0.45\end{array}$ & $\begin{array}{l}F=0.00 \\
p=0.97\end{array}$ & $\begin{array}{l}F=1.65 \\
p=0.21\end{array}$ & $\begin{array}{l}F=0.10 \\
p=0.75\end{array}$ \\
\hline
\end{tabular}

${ }^{a}$ Statistically significant difference $(p=0.05)$, Tukey's studentized range test.

\section{DISCUSSION}

In only a few studies of character variation in astigmatid mites has the role of allometry or environmental influence been investigated. OConnor and Reisen (1978) showed that simple allometry accounted for the extreme male polymorphism in Chiroptoglyphus americanus (Rosensteiniidae). Griffiths (1970) noted that individuals of Acarus siro (Acaridae) reared on a 'rich diet' had longer idiosomal setae than those reared on a 'poor diet'. Gerson and Capua 


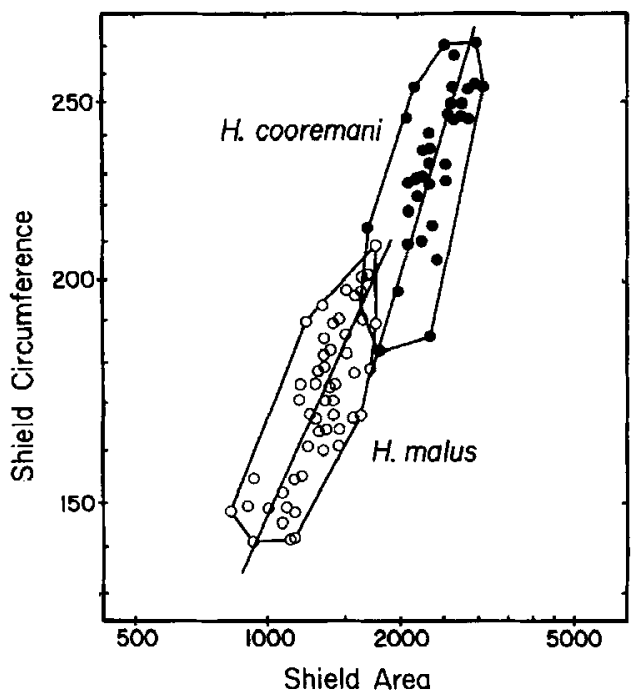

Fig. 10. The regression of shield circumference vs shield area for $H$. malus and $H$. cooremani. The line of best fit was calculated using major-axis regression.

(1982) reared the bulb mite, Rhizoglyphus robini (Acaridae) on three diets of decreasing nutritive value (peanuts, peanut extract and filter paper). They showed that the morphological structures and setal lengths used in taxonomic diagnoses can vary with diet.

From the present study, it is clear that culture temperature and resource can have important allometric influences both on the structural body components such as the prodorsal shield and on sensory components such as the tactile setae in Hemisarcoptes. The ecophenotypic effects on particular structures cannot be determined a priori, as evidenced by the differential responses of closely related species in our experiments. Even very closely related species may differ in their patterns of response both in kind and in magnitude.

Hemisarcoptes cooremani naturally ranges from the far southern United States to northern South America and throughout the Antilles. Hemisarcoptes malus is allopatrically distributed to the north, ranging from southern Canada to northern Louisiana, westward to the Rocky Mountains. In our experiments, $H$. cooremani expressed a greater range of character variance in relation to the experimental conditions than did $H$. malus. This correlates with the fact that $H$. cooremani normally experiences a relatively moderate and stable diurnal and seasonal regime (tropical and subtropical), whereas $H$. malus survives seasonal temperature fluctuations of $50^{\circ} \mathrm{C}$ or greater in the northern part of its range and 
TABLE 5

\begin{tabular}{llll}
$\begin{array}{l}\text { Means }( \pm \mathrm{SD}) \text { for the shield circumference and area for females of } H . \\
\text { malus and } H \text {. cooremani } \text { at three temperatures and on two hosts }\end{array}$ \\
\hline Temperature/host & $n$ & $\begin{array}{l}\text { Circumference } \\
(\mu \mathrm{m})\end{array}$ & $\begin{array}{l}\text { Area } \\
\left(\mu \mathrm{m}^{2}\right)\end{array}$ \\
\hline H. malus & & & \\
$15^{\circ} \mathrm{C}$ & 40 & $171 \pm 10^{\mathrm{a}}$ & $1339 \pm 243^{\mathrm{a}}$ \\
$24^{\circ} \mathrm{C}$ & 40 & $179 \pm 14^{\mathrm{a}}$ & $1400 \pm 185^{\mathrm{a}}$ \\
$30^{\circ} \mathrm{C}$ & 40 & $168 \pm 17^{\mathrm{a}}$ & $1291 \pm 211^{\mathrm{a}}$ \\
A. aurantii (lemon) & 60 & $174 \pm 16^{\mathrm{a}}$ & $1347 \pm 188^{\mathrm{a}}$ \\
A. nerii (potato) & 60 & $170 \pm 17^{\mathrm{a}}$ & $1339 \pm 205^{\mathrm{a}}$ \\
H. coormemani & & & \\
$15^{\circ} \mathrm{C}$ & 16 & $207 \pm 27^{\mathrm{a}}$ & $2177 \pm 483^{\mathrm{a}}$ \\
$24^{\circ} \mathrm{C}$ & 40 & $241 \pm 18^{\mathrm{b}}$ & $2445 \pm 256^{\mathrm{b}}$ \\
$30^{\circ} \mathrm{C}$ & 40 & $232 \pm 21^{\mathrm{b}}$ & $2431 \pm 378^{\mathrm{b}}$ \\
A. aurantii (lemon) & 52 & $252 \pm 22^{\mathrm{a}}$ & $1337 \pm 378^{\mathrm{a}}$ \\
A. nerii (potato) & 44 & $239 \pm 17^{\mathrm{a}}$ & $2461 \pm 301^{\mathrm{a}}$ \\
\hline
\end{tabular}

Significance: $p=0.05$, Tukey's studentized range test.

Means followed by the same letter are not significantly different from one another.

diurnal fluctuations of as much as $15^{\circ} \mathrm{C}$ are not uncommon. It would appear that $H$. malus has developed a more stable expression of character variance across a broader range of environmental influences, perhaps due to stabilizing selection pressures.

Higher environmental temperatures resulted in a smaller mean body size for both species. If the growth rate is inversely correlated with the length of time required to complete a developmental increment, the trend for a smaller body size in Hemisarcoptes may be correlated with a relatively faster growth rate at higher seasonal temperatures.

The observation that a shift in food resources (host species) has minimal effects on both $H$. malus and $H$. cooremani is consistent with the fact that, although Hemisarcoptes species are obligate specialist predators of diaspidid scale insects, within that family (Diaspididae) they are generalists in their diet. This particular family of scale insects is large and exhibits considerable morphological (and presumably physiological and chemical) variation. An estimate of the number of genera included is approximately 340 , including an estimated 1700 species, but possibly only half of the extant species have been described (Borchsenius, 1966). Hemisarcoptes has been found in association with many of these species (Gerson et al., 1990) and readily transfers from host to host (M. A. Houck, personal observation).

In conclusion, our experiments have demonstrated that plasticity in morphological character development correlates with environmental variables 
in the characters that we studied. However, even considering that the characters evaluated in this study are allometrically constrained by the experimental parameters, taken together the species-specific patterns of shield complexity, shield size and setal lengths are sufficiently distinctive to allow the diagnosis and identification of these two North American species. Caution is warranted, however, when considering the complexity of the prodorsal shield as a key character, as it appears to be a continuous character (not discrete) dictated by the body size. Larger $H$. malus could be mistaken for small $H$. cooremani and vice versa in a geographic range where the body size is similarly affected by the temperature. Perhaps the most useful character for diagnosis would be the sce setal pair because it is so distinctive. It is relatively shorter in the larger of the two species, $H$. cooremani, which is counter to the general pattern of an increase in character size with an increase in general body size. The degree to which the two species exhibit variation in their morphology under different environmental regimes appears to be inversely correlated with the environmental variation the two species encounter across their natural ranges.

\section{ACKNOWLEDGEMENTS}

We would like to thank Rod Summy (US Department of Agriculture) and Victor French (Texas A \& M Citrus Center) for assisting in the location of the collection sites and for generously providing working space in Weslaco, Texas. Robert F. Luck provided the California red scales. Richard E. Strauss added useful comments on the manuscript. This work was partially supported by the National Science Foundation (BSR no. 83-07711 to B.M.O. and M.A.H.) and BARD (no. IS-1397-87 no. US-2359-93C to M.A.H.).

\section{REFERENCES}

Borchsenius, N. S. 1966. A Catalogue of the Armoured Scale Insects (Diaspididae) of the World. Academy of Sciences of USSR, Zoology Institute, Moscow and Leningrad.

Gerson, U. and Capua, S. 1982. Allometric variation in Rhizoglyphus robini Claparede (Acari: Astigmata: Acaridae). Israel J. Entomol. 16: 69-72.

Gerson, U., OConnor, B. M. and Houck, M. A. 1990. Acari. In Armored scale insects, their biology, natural enemies and control, Vol. B, D. Rosen (ed.), pp. 77-97. Elsevier Science Publishers, Amsterdam.

Griffiths, D. A. 1970. A further systematic study of the genus Acarus L., 1758 (Acaridae, Acarina), with key to species. Bull. Br. Mus. (Nat. History) Zool. 19: 85-118.

Griffiths, D. A., Atyeo, W. T., Norton, R. A. and Lynch, C. A. 1990. The idiosomal chaetotaxy of astigmatid mites. J. Zool. (London) 220: 1-32.

Harvey, P. K. 1981. A simple algorithm for the unique characterization of convex polygons. Comput. Geosci. 7: 387-392.

Houck, M. A. and OConnor, B. M. 1990. Ontogeny and life history of Hemisarcoptes cooremani (Acari: Hemisarcoptidae). Ann. Entomol. Soc. Am. 83: 161-205. 
OConnor, B. M. and Reisen, W. 1978. Chiroptoglyphus, a new genus of mites associated with bats with comments on the family Rosensteiniidae (Acari: Astigmata). Int. J. Acarol. 4: 179194.

SAS Institute 1982. User's Guide: Statistics. SAS Institute, Cary, NC.

Shimer, H. 1868. Notes on the 'Apple bark-louse' (Lepidosaphes conchiformis, Gmelin sp.) with a description of a supposed new Acarus. Trans. Am. Entomol. Soc. 1: 361-374.

Thomas, H. A. 1961. Vidia (Coleovidia) cooremani, new subgenus and new species, and notes on the life history (Acarina: Saproglyphidae). Ann. Entomol. Soc. Am. 54: 461-463. 